\title{
PRODUCTION AND CHARACTERIZATION OF TYROSINASE ACTIVITY IN PYCNOPORUS SANGUINEUS CCT- 4518 CRUDE EXTRACT
}

\section{Lívia Teixeira Duarte, Joyce Batista Tiba, Mariângela Fontes Santiago, Telma Alves Garcia, Maria Teresa Freitas Bara*}

Laboratório de Enzimologia, Faculdade de Farmácia, Universidade Federal de Goiás, Goiânia, GO, Brasil.

Submitted: November 03, 2009; Returned to authors for corrections: April 15, 2011; Approved: January 16, 2012.

\begin{abstract}
Tyrosinase is an enzyme of industrial interest. The production and characterization of tyrosinase from $P$. sanguineus CCT-4518 were investigated. The selection of inductors, luminosity influence, inoculum size and type of culture medium on the production of tyrosinase and the effect of inhibitors on enzyme activity were performed. Optimum conditions for intracellular tyrosinase production was observed after 2 days using $0.15 \%$ L-tyrosine as inducer, in the presence of light, with inoculum size of 10 mycelium discs, using $2 \%$ malt extract broth medium, incubated at $30^{\circ} \mathrm{C}$, and constant agitation of $150 \mathrm{rpm}$. Tyrosinase activity was completely inhibited by the addition of $6 \mathrm{mM}$ salicylhydroxamic acid or phenylthiourea, however an inhibition of $4.15 \%$ was recorded by the addition of $0.1 \mathrm{mM}$ sodium azide. No inhibition could be detected in case of $0.1 \mathrm{mM}$ phenyl methanesulfonyl fluoride addition. Optimal conditions for intracellular tyrosinase activity using L-dopa as substrate were observed at $\mathrm{pH} 6.6$ and $45^{\circ} \mathrm{C}$. Thermal stability studies indicated that the enzyme is stable at $45^{\circ} \mathrm{C}$ for 15 minutes. Higher temperatures decreased tyrosinase activity. Enzyme production was confirmed by non-denaturing polyacrylamide gel electrophoresis and the protein profile was investigated by denaturing polyacrylamide gel electrophoresis.
\end{abstract}

Key words: Pycnoporus sanguineus, white-rot fungi, tyrosinase, MBTH, biotechnology.

\section{INTRODUCTION}

Tyrosinase (E.C.1.14.18.1) catalyses the o-hydroxylation of monophenols (monophenolase activity) and the oxidation of o-diphenols to reactive o-quinones (diphenolase activity), both reactions using molecular oxygen (22). The o-quinones undergo non-enzymatic reactions with various nucleophiles, producing intermediates, which associate spontaneously in dark brown pigments (8). The monophenolase activity distinguishes tyrosinase from other phenol-oxidizing enzymes, such as laccase and peroxidase (26). Accordingly, failure to oxidize L-tyrosine and ability to oxidize 3,4-dihydroxy-Lphenylalanine (L-DOPA) can be taken as a proof of laccase activity (22).

In fungi, tyrosinases are associated with melanin production, which constitute a mechanism of defense to stress such as UV radiation, free radicals, gamma rays, dehydratation and extreme temperatures and contribute to the fungal cell-wall

*Corresponding Author. Mailing address: Laboratório de Enzimologia, Faculdade de Farmácia, Universidade Federal de Goiás, Av. Universitária com Primeira Avenida s/n, Setor Universitário CEP: 74605-220 - Goiânia - GO. Brazil.; Tel.: +55(62)3209-6182.; E-mail: mbara@ farmacia.ufg.br 
resistance against hydrolytic enzymes, avoiding cellular lysis (1).

Tyrosinases have many biotechnological and industrial applications, including treatment of wastewater containing phenols and dyes $(5,6,13)$, synthesis and bioconversion of odiphenol drugs, like L-DOPA $(7,17,18)$ and protein crosslinking in food technology (21).

No previous reports about tyrosinase production by $P$. sanguineus CCT-4518 (a strain isolated from Amazon forest), have been published yet, although other strains showed tyrosinase production (16). In this paper we report the optimization of in vitro culture conditions of Pycnoporus sanguineus CCT-4518 for the production of tyrosinase and the characterization of the tyrosinase produced.

\section{MATERIALS AND METHODS}

\section{Organisms and culture conditions}

The white-rot fungus Pycnoporus sanguineus CCT-4518 was obtained from Fundação André Tosello, Campinas, São Paulo, Brazil. Ten $5 \mathrm{~mm}$ diameter mycelium discs were inoculated in $50 \mathrm{~mL}$ of malt extract broth (Merck, Darmastadt, Germany) plus substrate $(4,19,28)$. Cultures were grown in conical flasks $(250 \mathrm{ml})$ with shaking $(150 \mathrm{rpm})$ at $30^{\circ} \mathrm{C}$ for 7 days (16). Aliquots were withdrawn daily for determination of enzymatic activity.

\section{Agar spot tests for tyrosinase}

Petri dishes containing potato dextrose agar (PDA) (Acumedia, Maryland, USA) and $100 \mathrm{mg} . \mathrm{L}^{-1}$ p-cresol (Sigma, St. Louis, USA) were inoculated with one agar plug from the culture of $P$. sanguineus and incubated at room temperature for 7 days. Outgrowing mycelial mats received drops of $0.1 \mathrm{M}$ cresol in ethanol to their colony margins. Tyrosinase reacts with p-cresol to form a yellow to red color. Tests were performed in triplicate and data was obtained by visual comparison with a control plate without p-cresol (14).

\section{Preparation of cell-free extracts}

Cell lysates were prepared daily. Mycelia from three conical flasks were collected by vacuum filtration in filter paper, resuspended in $5 \mathrm{~mL}$ of sodium phosphate buffer $[0.1 \mathrm{M}$ sodium phosphate $\mathrm{pH}$ 6.8, $550 \mathrm{mM}$ sorbitol (Sigma, St. Louis, USA), 0.5 mM PMSF (phenylmethanesulfonyl fluoride) (Acros Organics, New Jersey, USA), $6.5 \mu \mathrm{L}$ of protease inhibitor cocktail (Sigma, St. Louis, USA)], lysed in ultrasonic bath. Cell debris were removed by centrifugation at $4000 \mathrm{rpm}$ for 10 minutes. The resulting supernatant constituted the cell-free extract and was used immediately for enzymatic activity assays (16).

Tyrosinase production was optimized by the addition of $0.3 \%$ of the following inducers in the culture medium: Ltyrosine (Acros Organics, New Jersey, USA), L-dopa (L-3,4 dihydroxyphenylalanine) (Acros Organics, New Jersey, USA), cafeic acid (3,4 dihydroxycinnamic acid) (Acros Organics, New Jersey, USA), 4-hydroxyphenyl-2 propionic acid and guaiacol (Sigma, St. Louis, USA). The best inducer was also tested at $0.15 \%$ and $0.075 \%$. Luminosity conditions (presence and absence of light), quantity of biomass (10 and 20 mycelium discs) and culture media (potato dextrose broth and malt extract broth) were investigated for the enzymatic production.

\section{Protein and enzymatic activity assays}

Protein concentration was determined by the Bradford's method (3), with bovine serum albumin (BSA) (Sigma, St. Louis, USA) as standard. Laccase activity was determined at $30{ }^{\circ} \mathrm{C}$ for 5 minutes using $0.5 \mathrm{mM}$ ABTS (2,2-azino-bis (3ethylbezothiazoline-6-sulphonic acid) diammonium salt) (Sigma, St. Louis, USA) $\left(\varepsilon 420=3.6 \times 10^{4} \mathrm{M} . \mathrm{cm}^{-1}\right)(2)$.

The reaction mixture contained $100 \mu \mathrm{L}$ of substrate, sodium acetate buffer (136 mM, pH 5), and $100 \mu \mathrm{l}$ of the sample. The oxidation of the substrates was measured after 5 minutes, with a spectrophotometer at $420 \mathrm{~nm}$. Tyrosinse activity was determined at $30{ }^{\circ} \mathrm{C}$ for 10 minutes using $3.2 \mathrm{mM}$ 
L-DOPA $\left(\varepsilon 505=2.9 \times 10^{4} \mathrm{M} . \mathrm{cm}^{-1}\right)(27)$. The reaction mixture contained sodium acetate buffer (50 mM, pH 5), $3.2 \mathrm{mM} \mathrm{L}$ DOPA, $5 \mathrm{mM}$ MBTH (3-methyl-2-benzothiazolinone hydrazone) (Sigma, St. Louis, USA), 2\% n-n'dimethylformamide, $0.1 \mathrm{mM}$ sodium azide and $100 \mu \mathrm{L}$ of intracellular crude extract. After incubation at $37{ }^{\circ} \mathrm{C}$ for 10 minutes the reaction was stopped by adding $500 \mu \mathrm{L}$ of $1 \mathrm{M}$ perchloric acid and absorbance was measured at $505 \mathrm{~nm}$. One unit of enzyme activity was defined as the amount of enzyme required to oxidize $1 \mu \mathrm{M} \mathrm{min}{ }^{-1}$ of the substrate under standard assay conditions.

\section{Inhibitory effect of different compounds}

The effect of inhibitors on tyrosinase and laccase activities was carried out after incubation at $37{ }^{\circ} \mathrm{C}$ for 10 minutes. The residual activities were measured following the assay procedure, and the degree of inhibition was expressed as the percentage of the enzyme activity in the control sample. 0.1 $\mathrm{mM}$ sodium azide, $0.1 \mathrm{mM}$ PMSF, $6 \quad \mathrm{mM}$ PTU (phenylthiourea) (Sigma, St. Louis, USA) and $6 \mathrm{mM}$ SHAM (salicylhydroxamic acid) (Sigma, St. Louis, USA) were added to the reaction mixture containing purified laccase (provided by Dr Telma Garcia, Faculdade de Farmácia - Universidade Federal de Goiás, Brazil) and commercial tyrosinase from mushroom (Sigma, St. Louis, USA).

\section{Enzyme characterization}

Sodium dodecyl sulfate-polyacrylamide gel electrophoresis (SDS-PAGE) was carried out according to the method of Laemmli (20) using a $10 \%$ cross-linked polyacrylamide gel. Coomassie staining was performed to visualize protein bands from the intracellular crude extract on the gel and molecular weight was determined by comparison with protein marker (Fermentas Life Sciences). Tyrosinase activity was detected in the intracellular crude extract using LDOPA as a substrate. After non-denaturing PAGE (10\% w/v), gels were washed and soaked in citrate/phosphate buffer (170
$\mathrm{mM}, \mathrm{pH}$ 6.6) for 20 minutes at room temperature under mild agitation, in order to exchange the buffer system. The buffer was drawn off, and the gels were then incubated in $170 \mathrm{mM}$ citrate/phosphate buffer ( $\mathrm{pH}$ 6.6) containing 5 mM L-DOPA, 2 $\mathrm{mM}$ MBTH, 3\% ethanol and $0.1 \mathrm{mM}$ sodium azide. Protein bands exhibiting tyrosinase activity stained in red (25).

\section{Enzyme properties}

The effect of $\mathrm{pH}$ on enzyme activity was determined by varying the $\mathrm{pH}$ of the reaction mixtures using $170 \mathrm{mM}$ sodium citrate/ sodium phosphate buffer ( $\mathrm{pH}$ 3.6-7.0) and $170 \mathrm{mM}$ sodium phosphate buffer $(\mathrm{pH}$ 7.6-8.0). The effect of temperature on enzymatic activity was determined at $\mathrm{pH} 6.6$, in the range from $25{ }^{\circ} \mathrm{C}$ to $70^{\circ} \mathrm{C}$. Thermal stability was verified by incubating the enzyme at 45,50 and $55^{\circ} \mathrm{C}$ during $0,15,30$, 45, 60 and 90 minutes, and the residual activities were determined at assay temperature.

\section{Statistical analysis}

Statistical analysis was carried out according to Valeriano et al. (28). Assays were carried out in triplicate, and standard deviation did not exceed $10 \%$ of the average values. Y error bars indicate the standard error among replicates.

\section{RESULTS}

\section{Agar spot tests for tyrosinase}

This qualitative test was conducted to verify the tyrosinase production by $P$. sanguineus. In the sixth day of observation, we noticed the appearance of light reddish staining in the mycelium. Then a few drops of p-cresol $0.1 \mathrm{M}$ solution were added and in the seventh day of incubation the development of a more intense reddish brown colour in the mycelium was observed. This colour indicates tyrosinase production.

\section{Tyrosinase production}

The quantification of intracellular and extracellular 
tyrosinase activities in $P$. sanguineus extract showed that tyrosinase is an intracellular enzyme in this fungus. No extracellular tyrosinase activity was observed during the 7 days of incubation. The intracellular-tyrosinase activity peaks in the second day of incubation (18.96 U/L of tyrosinase activity) (Fig. 1).

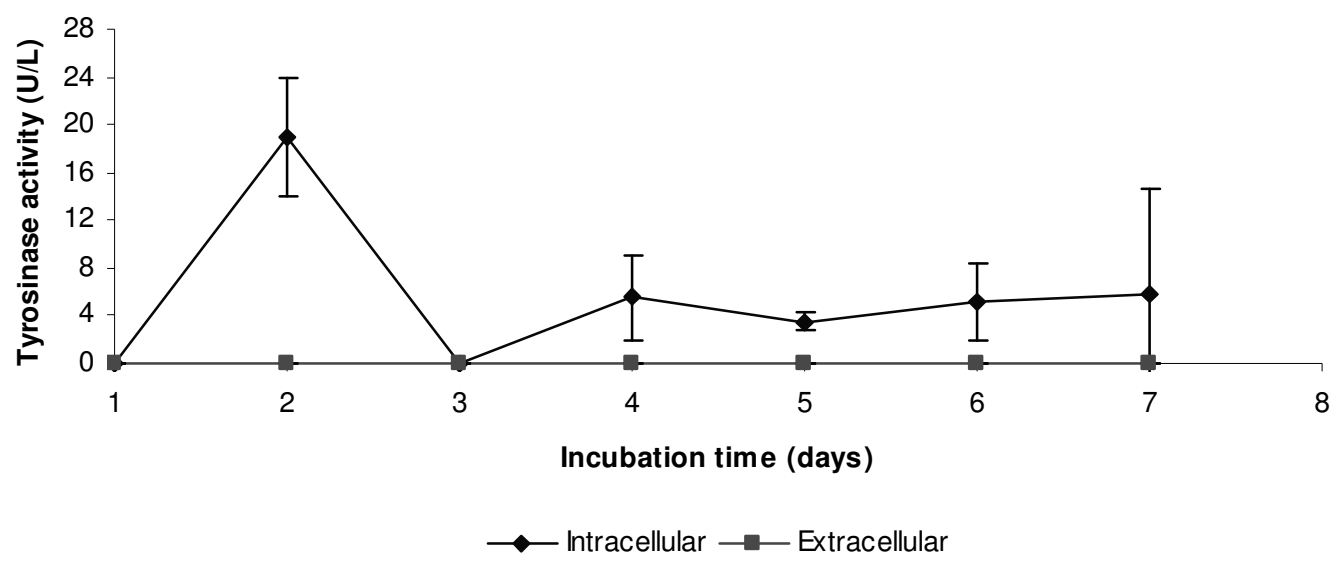

Figure 1. Intracellular and extracellular tyrosinase activities in P. sanguineus extract. Assays were done in sodium acetate buffer (50 mM, pH 5), at $37^{\circ} \mathrm{C}$.

\section{Effect of inducers}

L-tyrosine at $0.15 \%$ induced intracellular tyrosinase production at levels considerably higher than the other tested inducers (L-DOPA, cafeic acid, 4-hydroxiphenyl-2-propionic acid and guaiacol). The values of tyrosinase activity (U/L) and the standard deviations (\%) were, respectively: $9.77 \pm 2.40$ (second day); $10.70 \pm 3.19$ (day 4); $4.98 \pm 8.26$ (day 5); $8.90 \pm$ 8.91 (day 6) and $14.61 \pm 10$ (day 7) when L-tyrosine was used as inducer (Fig.2).The maximum production in the absence of inducers was $6.34 \mathrm{U} / \mathrm{L} \pm 10 \%$, showing the importance of inducers for tyrosinase production.

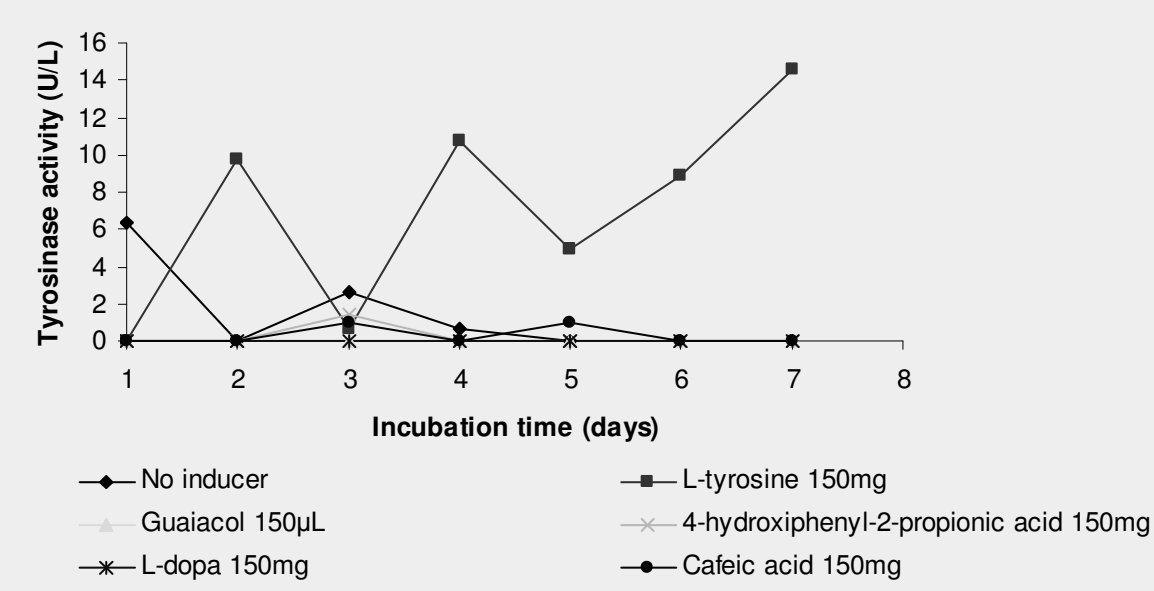

Figure 2. Inducers selection for tyrosinase production by P. sanguineus. Assays were done in sodium acetate buffer (50 $\mathrm{mM}, \mathrm{pH}$ $5)$, at $37^{\circ} \mathrm{C}$. 


\section{Luminosity influence}

When the incubation was performed in the absence of light, the enzymatic production peaked in the second day
(18.72 U/L of tyrosinase activity). On the other hand, in presence of light, 3 peaks of production were observed in the second, fourth and seventh days of incubation (Table 1).

Table 1. Influence of luminosity on tyrosinase production by $P$. sanguineus

\begin{tabular}{ccc}
\hline \multirow{2}{*}{ Incubation time (days) } & \multicolumn{2}{c}{ Tyrosinase activity (U/L) } \\
Absence of light \pm DPR
\end{tabular}

\section{Effect of inoculum size}

The higher tyrosinase production when incubating 10 mycelium discs occurred in the second day of incubation (18.96 $\mathrm{U} / \mathrm{L}$ of tyrosinase activity). When using 20 mycelium discs, optimum tyrosinase production occurred in day $6(23.22 \mathrm{U} / \mathrm{L}$ of tyrosinase activity) (Table 2). Despite the higher activity found using 20 mycelium discs, this activity occurred in the day 6 , four days later than the peak using 10 mycelium discs.

Table 2. Correlation between biomass production and tyrosinase activity

\begin{tabular}{ccc}
\hline \multirow{2}{*}{ Incubation time (days) } & \multicolumn{2}{c}{ Tyrosinase activity (U/L) } \\
& $\mathbf{1 0}$ mycelium discs \pm DPR & 20 mycelium discs \pm DPR \\
\hline 1 & $0.00 \pm 0.00$ & $0.00 \pm 0.00$ \\
2 & $18.97 \pm 5.02$ & $9.24 \pm 2.33$ \\
3 & $0.00 \pm 0.00$ & $10.83 \pm 6.31$ \\
4 & $5.90 \pm 10.00$ & $14.39 \pm 4.74$ \\
5 & $3.77 \pm 10.00$ & $10.79 \pm 6.37$ \\
6 & $4.80 \pm 10.00$ & $23.22 \pm 7.54$ \\
7 & $5.86 \pm 8.71$ & $8.45 \pm 4.32$ \\
\hline
\end{tabular}

\section{Effect of culture medium}

Optimal tyrosinase production was observed when potato dextrose broth was used in the second, third and sixth days. When malt extract broth $2 \%$ was used, the optimum tyrosinase production was in the second day of incubation (Table 3). For this reason malt extract broth $2 \%$ was chosen for tyrosinase production, since this peak occurred in a shorter incubation time (2 days) and the enzymatic activity value was higher than the others.

Table 3. Influence of culture media on tyrosinase production by $P$. sanguineus

\begin{tabular}{ccc}
\hline $\begin{array}{c}\text { Incubation time } \\
\text { (days) }\end{array}$ & \multicolumn{2}{c}{ Tyrosinase activity (U/L) } \\
\hline 1 & Malt extract broth 2\% \pm DPR & Potato dextrose broth \pm DPR \\
2 & $0.00 \pm 0.00$ & $0.00 \pm 0.00$ \\
3 & $18.97 \pm 5.02$ & $12.53 \pm 5.53$ \\
4 & $0.00 \pm 0.00$ & $14.71 \pm 5.14$ \\
5 & $5.90 \pm 10.00$ & $3.93 \pm 10.00$ \\
6 & $3.77 \pm 10.00$ & $5.44 \pm 7.35$ \\
7 & $4.80 \pm 10.00$ & $14.22 \pm 7.04$ \\
\hline
\end{tabular}




\section{Inhibitory effect of different compounds}

Laccase and tyrosinase activities were investigated after 10 minutes of incubation of the enzyme with several inhibitory compounds (Table 4).

In tests performed with purified laccase, an activity of 103.83 $\mathrm{U} / \mathrm{L}$ was found in the absence of sodium azide and an activity of $2.78 \mathrm{U} / \mathrm{L}$ was found in the presence of sodium azide. Soon, there was a $97.32 \%$ inhibition of laccase sample by sodium azide which is a classical inhibitor of metal containing oxidases.

On testing the effect of SHAM and PTU addition $(6 \mathrm{mM})$ on laccase activity, it was noticed that there is a pronounce decrease in the relative activities estimated as $3.62 \%(3.98 \mathrm{U} / \mathrm{L})$ and 4.62 $\%(5.074 \mathrm{U} / \mathrm{L})$ respectively as compared with the non-treated sample (100\%; $109.82 \mathrm{U} / \mathrm{L})$. Results obtained suggest that laccase is strongly inhibited by SHAM and PTU.

Sodium azide weakly affected the activity of tyrosinase, with the maintenance of $95.85 \%$ of its activity after incubation with 0.1 $\mathrm{mM}$ sodium azide. Despite this drop in tyrosinase activity, the use of sodium azide was chosen since for the accurate tyrosinase quantification in samples also containing laccase is essential that it be inhibited.

The tyrosinase activity in the absence of PMSF (21.72 U/ L) was not lower than the activity in the presence of the inhibitor (23.82 U/ L). Results suggest that PMSF does not inhibit tyrosinase. In addition, the tyrosinase activity was completely inhibited by $6 \mathrm{mM}$ SHAM and PTU.

Table 4. Effect of several inhibitory compounds on laccase and tyrosinase activities (incubation at $37^{\circ} \mathrm{C}$ for 10 minutes)

\begin{tabular}{cccc}
\hline Compound & Concentration $(\mathrm{mM})$ & Laccase relative activity $(\%)$ & Tyrosinase relative activity $(\%)$ \\
\hline None & - & 100 & 100 \\
Sodium azide & 0.1 & 2.68 & 95.85 \\
PMSF & 0.1 & - & 100 \\
PTU & 6 & 4.62 & 0 \\
SHAM & 6 & 3.62 & 0 \\
\hline
\end{tabular}

\section{Electrophoresis and enzymatic activities in gels}

SDS-PAGE of the intracellular crude extract of $P$. sanguineus showed four bands of low intensity (estimated sizes of $95 \mathrm{kDa}, 78 \mathrm{kDa}, 64 \mathrm{kDa}$ and $54 \mathrm{kDa}$ ) (Fig. 3).

Tyrosinase activity gel staining revealed one red zone of tyrosinase (Fig. 4).

The substrate L-dopa used in the activity staining of tyrosinase is also a substrate for laccase. As the laccase inhibitor (sodium azide) was not used in this test, the bands shown laccase activity were also stained. Commercial tyrosinase and crude extract of $P$. sanguineus were previously quantified for tyrosinase and laccase activities (Data not shown). Laccase activity was null in commercial tyrosinase while crude extract presented laccase and tyrosinase activities, confirming the identity of the bands shown in Fig. 4.

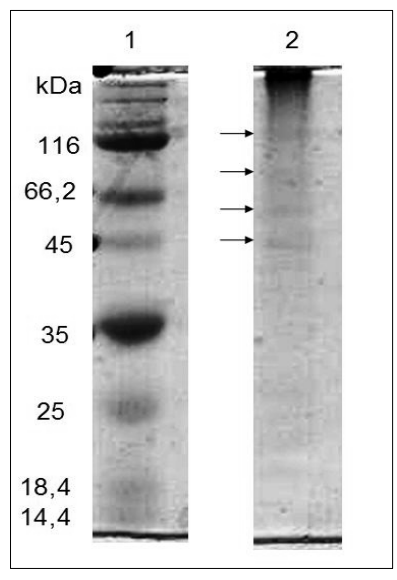

Figure 3. SDS-PAGE pattern of the intracellular crude extract of $P$. sanguineus Coomassie stained. Electrophoresis was carried out using a $10 \%$ cross-linked polyacrilamide gel. Lane 1: molecular mass marker proteins. Lane 2: intracellular crude extract of $P$. sanguineus. 


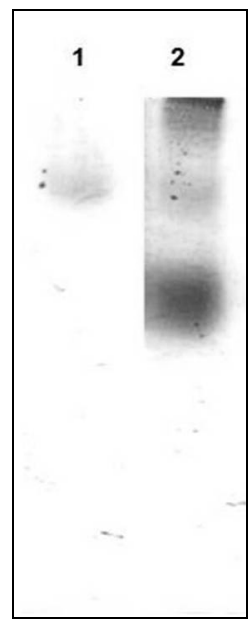

Figure 4. Activity staining of tyrosinase. Lane 1: protein band of commercial tyrosinase exhibiting tyrosinase activity is marked. Lane 2: protein band of $P$. sanguineus intracellular crude extract exhibiting tyrosinase activity is marked.

\section{Thermal stability behavior}

$\mathrm{pH}$ profile of $P$. sanguineus CCT-4518 tyrosinase showed optimum activity at $\mathrm{pH}$ 6.6. Tyrosinase was more active at $45^{\circ} \mathrm{C}$, though it showed considerable activity over the range of $40-60^{\circ} \mathrm{C}$. The crude extract presented a fast loss of activity when pre-incubated for relatively short periods at 50 and $55^{\circ} \mathrm{C}$. Pre-incubation of tyrosinase at $50^{\circ} \mathrm{C}$ for 15 minutes resulted to the reduction of activity by about $53.87 \%$, however a complete loss of activity was recorded with samples pre-incubated at $50^{\circ} \mathrm{C}$ and $55^{\circ} \mathrm{C}$ for 45 and 15 minutes respectively. The enzyme kept $50 \%$ of relative activity after 45 minutes of incubation (Data not shown).

\section{DISCUSSION}

The practical application of tyrosinases in biotechnology requires large quantities of enzymes; hence, the identification of new Pycnoporus strains as potential producers of tyrosinases is of biotechnological importance (16).

Initially, to investigate the potential of this strain to produce tyrosinase the qualitative test was performed.
According to Gramss et al. (14), the appearance of yellow to red color at the ends of fungal colony margins, after adding $\mathrm{p}$ cresol, is an indication of the presence of intracellular tyrosinase. This is in accordance with Mayer and Harel (23), who stated that tyrosinase was an intracellular enzyme in most fungi they investigated. The tyrosinase (cresolase) test was not influenced by laccase or peroxidase. The indicator, p-cresol, is stained reddish brown by tyrosinase only, but remains colourless by laccase and peroxidase (14).

Once detected the ability of the amazonic strain $P$. sanguineus CCT-4518 to produce the enzyme of interest, the work was then directed towards optimization of its in vitroproduction. The ideal conditions of $P$. sanguineus cultivation for tyrosinase production were determined and $0.15 \% \mathrm{~L}$ tyrosine was the best inducer, in the presence of light, with 10 mycelium discs as inoculum, medium malt extract broth $2 \%$, incubation at $30^{\circ} \mathrm{C}, 150 \mathrm{rpm}$ agitation, during 2 days. To our knowledge this is the first report of tyrosinase production optimization in P.sanguineus. In this connection Halaouli et al. (16) reported that optimum incubation temperature for $\mathrm{P}$ sanguineus $\mathrm{CBS} 614.73$ is $30^{\circ} \mathrm{C}$ in agreement with our results.

Despite the higher enzimatic activity observed during the incubation in the absence of light, the preferred condition for the tyrosinase production was in the presence of light, in an attempt to inhibit the laccase production, since it has increased production in the dark (10).

Aiming to investigate the effect of compounds inhibiting tyrosinase activity of $P$. sanguineus (CCT-4518) and having the parallel laccase production in the cultivation conditions $\left(0.15 \%\right.$ L-tyrosine, in the presence of light, at $30^{\circ} \mathrm{C}$ and 150 rpm agitation) been noticed, the inhibition of this interfering was initially searched. Laccase was almost completely inhibited by sodium azide, which is a classical inhibitor of metal containing oxidases $(11,27)$. Laccase was found to be inhibited by $6 \mathrm{mM}$ SHAM $(96.38 \%)$ or PTU $(95.38 \%)$, suggesting that laccase is also inhibited by SHAM and PTU, although these inhibitors are traditionally considered specific 
tyrosinase inhibitors $(15,24,25,30)$.

$P$. sanguineus (CCT-4518) tyrosinase barely affected in reaction mixtures containing $0.1 \mathrm{mM}$ of sodium azide or PMSF. There is no previous report of tyrosinase inhibition by sodium azide or PMSF. P. sanguineus (CCT 4518) tyrosinase activity was completely inhibited by PTU and SHAM at $6 \mathrm{mM}$ final concentration. According to Gunther et al. (15), Miranda et al. (24), Rescigno et al. (25) and Winder (30), the tyrosinase is strongly inhibited by PTU and SHAM.

The protein profile in electrophoresis allows monitoring the conditions of production and the purity degree of the purified enzyme. A recent article by Fan and Flurkey (9), reports two major stained bands of protein along with a less stained protein, in a sample containing purified tyrosinase of Portabella mushrooms. The estimated sizes of the bands were $43 \mathrm{kDa}, 48 \mathrm{kDa}$ and $60 \mathrm{kDa}$. It is supposed that the bands in the 43-48 $\mathrm{kDa}$ are the active proteolyzed forms of tyrosinase that many other investigators have observed (12, 29, 31). According to Halaouli et al. (16), the P. sanguineus (CBS 251 614.73 ) purified tyrosinase has $45 \mathrm{kDa}$ and is a monomeric enzyme. To identify which of the four bands detected shows tyrosinase activity in this study it is necessary to implement the purification of the enzyme.

The activity determination is a tool to confirm an assumed activity of the found protein and evaluate the number of isoforms produced by microorganisms. Under partially denaturing SDS-PAGE, with samples not boiled or treated with reducing agents, several isoforms of tyrosinase were detected in crude extracts of Portabella mushroom (9), contrasting the observed in this work, where only one tyrosinase isoform was verified in the non denaturing PAGE.

When the commercial tyrosinase was stained for laccase and tyrosinase activities by Rescigno et al. (25), protein band exhibiting laccase activity appeared bellow the protein band exhibiting tyrosinase activity, as well as the bands observed in this study.

Due to the still limited number of reports about tyrosinase and its biotechnological applications, it is necessary to have knowledge about the enzyme under study. In the biochemical characterization, the optimum $\mathrm{pH}$ of intracellular tyrosinase production by $P$. sanguineus (CCT 4518) was found to be 6.6 which coincides with the corresponding value found in case of the purified tyrosinase from P. sanguineus (CBS 614.73) $(\mathrm{pH}$ 6.5-7.0) (16). The optimum temperature for $P$. sanguineus (CCT-4518) was $45^{\circ} \mathrm{C}$. The $P$. sanguineus (CBS 614.73) purified tyrosinase has $60-65^{\circ} \mathrm{C}$ of the optimum temperature and remained active in a wide range of temperature $\left(25-70^{\circ} \mathrm{C}\right)$ (16). The $P$. sanguineus (CCT-4518) tyrosinase showed to be less thermostable, maintaining only about $50 \%$ activity after 15 minutes incubation at $50^{\circ} \mathrm{C}$. Differently, the $P$. sanguineus (CBS 614.73) purified tyrosinase showed to be more thermostable, presenting considerable stablility below $60^{\circ} \mathrm{C}$. At $50{ }^{\circ} \mathrm{C}$, the enzyme half-life was longer than 120 minutes, while at $60^{\circ} \mathrm{C}$ it was almost completely inactivated after 20 minutes of incubation (16).

In conclusion, $P$. sanguineus CCT-4518 produces one intracellular protein with tyrosinase activity when induced with L-tyrosine. Further study will be required to investigate the application of crude extract in compounds biotransformation, bioremediation and biosensors.

\section{ACKNOWLEDGEMENTS}

This work was supported by grants from Secretaria de Ciência e Tecnologia do Estado de Goiás (SECTEG-GO). We thank Debora Teixeira Duarte for reviewing the manuscript.

\section{REFERENCES}

1. Beel, A.A.; Wheeler, M.H. (1986). Biosynthesis and functions of fungal melanins. Annu. Rev. Phytopathol. 24, 411-451.

2. Bourbonnais, R.; Paice, M.G. (1990). Oxidation of non-phenolic substrates. An expanded role for laccase in lignin biodegradation. FEBS Lett. 267, 99-102.

3. Bradford, M.M. (1976). A rapid and sensitive method for the quantitation 
of microgram quantities of proteins utilizing the principle of protein-dye binding. Anal. Biochem. 72, 248-254.

4. Cavallazzi, J.R.P.; Kasuya, C.M.; Soares, M.A. (2005). Screening of inducers for laccase production by Lentinula edodes in liquid medium. Braz. J. Microbiol. 36, 383-387.

5. Chiacchierini, E.; Restuccia, D.; Vinci, G. (2004). Bioremediation of food industry effluents: recent applications of free and immobilised polyphenoloxidases. Food. Sci. Technol. Int. 10 (6), 373-382.

6. Duran, N.; Esposito, E. (2000). Potential applications of oxidative enzymes and phenoloxidase-like compounds in wastewater and soil treatment: a review. Appl. Catal. B. 28, 83-99.

7. Duran, N.; Rosa, M.A.; D'annibale, A.; Gianfreda, L. (2002). Applications of laccases and tyrosinases (phenoloxidases) immobilized on different supports: a review. Enzyme Microb. Technol. 31, 907-931.

8. Espin, J.C.; Morales, M.; Var.n, R.; Tudela, J.; Garcia-Canovas, F. (1995). A continuous spectrophotometric method for determining the monophenolase and diphenolase activities of apple polyphenol oxidase. Anal. Biochem. 231, 237-246.

9. Fan, Y.; Flurkey, W.H. (2004). Purification and characterization of tyrosinase from gill tissue of Portabella mushrooms. Phytochemistry. 65, 671-678.

10. Garcia, T.A.; Santiago, M.F.; Ulhoa, C.J. (2006). Properties of laccases produced by Pycnoporus sanguineus induced by 2,5-xylidine. Biotechnol. Lett. 28, 633-636.

11. Garcia, T.A.; Santiago, M.F.; Ulhoa, C.J. (2007). Studies on the Pycnoporus sanguineus laccase purified by hydrophobic interaction chromatography. Appl. Microbiol. Biotechnol. 75, 311-318.

12. Gerritsen, Y.A.M.; Chapelon, C.G.J.; Wichers, H.J. (1994). The low isoeletric point tyrosinase of Agaricus bisporus may be a glycoprotein. Phytochemistry. 35, 573-577.

13. Girelli, A.M.; Mattei, E.; Messina, A. (2006). Phenols removal by immobilized tyrosinase reactor in on-line high performance liquid chromatography. Anal. Chim. Acta. 580, 271-277.

14. Gramss, G.; Gunther, T.H.; Fritsche, W. (1998). Spot tests for oxidative enzymes in ectomycorrhizal, wood-, and litter decaying fungi. Mycol. Res. 102 (1), 67-72.

15. Gunther, T.H.; Perner, B.; Gramss, G. (1998). Activities of phenol oxidizing enzymes of ectomycorrhizal fungi in axenic culture and in symbiosis with Scots pine (Pinus sylvestris L.). J. Basic Microbiol. 38, 197-206.

16. Halaouli, S.; Asther, Mi.; Kruus, K.; Guo, L.; Hamdi, M.; Sigoillot, J.C.; Asther, M.; Lomascolo, A. (2005). Characterization of a new tyrosinase from Pycnoporus species with high potential for food technological applications. J. Appl. Microbiol. 98, 332-343.
17. Halaouli, S.; Asther, M. Sigoillot, J.C.; Hamdi, M.; Lomascolo, A. (2006). Fungal yrosinases: new prospects in molecular characteristics, bioengineering and biotechnological applications. J. Appl. Microbiol. $100,219-232$

18. Haq, I.; Ali, S.; Qadeer, M.A. (2002). Biosynthesis of L-DOPA by Aspergillus oryzae. Bioresour. Technol. 85, 25-29.

19. Herpoel, I.; Moukha, S.; Lesage-Meessen, L.; Sigoillot, J.C.; Asther, M. (2000). Selection of Pycnoporus cinnabarinus strains for laccase production. FEMS Microbiol. Lett. 183, 301-306.

20. Laemmli, U.K. (1970). Cleavage of structural proteins during the assembly of the head of bacteriophage T4. Nature. 227, 680-685.

21. Lantto, R. (2007). Protein cross-linking with oxidative enzymes and transglutaminase. Effects in meat protein systems. Espoo 2007. VTT Publications 642. $114 \mathrm{p}$.

22. Mayer, A.M. (1987). Polyphenol oxidases in plants - recent progress. Phytochemistry. 26, 11-20.

23. Mayer, A.M.; Harel, E. (1979). Review: Polyphenol oxidases in plants. Phytochemistry. 18, 193-215.

24. Miranda, M.; Bonfigli, A.; Zarivi, O.; Ragnelle, A.M.; Pacioni, G.; Botti, D. (1992). Truffle tyrosinase: Properties and activity. Plant. Sci. 81, 175182

25. Rescigno, A.; Zucca, P.; Fluekey, A.; Inlow, J.; Flurkey, W.H. (2007). Identification and discriminaton between some contaminant enzyme activities in commercial preparations of mushroom tyrosinase. Enzyme Microb. Technol. 41, 620-627.

26. Sanchez-Ferrer, A.; Rodriguez-Lopez, J.N.; Garcia-Canovas, F.; GarciaCarmona, F. (1995). Tyrosinase: a comprehensive review of its mechanism. Biochim. Biophys. Acta. 1247, 1-11.

27. Sugumaran, M. (1995). A caution about azide inhibition of enzymes associated with electrophilic metabolites. Biochem. Biophys. Res. Commun. 212, 834-839.

28. Valeriano, V.S.; Silva, A.M.F.; Santiago, M.F.; Bara, M.T.F.; Garcia, T.A. (2009). Production of laccase by Pycnoporus sanguineus using 2,5xylidine and ethanol. Braz. J. Microbiol. 40, 790-794.

29. Wichers, H.J.; Gerritsen, Y.A.M.; Chapelon, C.G.J. (1996). Tyrosinase isoforms from the fruitbodies of Agaricus bisporus. Phytochemistry. 43 (2), 333-337.

30. Winder, A.J. (1994). A stopped spectrophotometric assay for the dopa oxidase activity of tyrosinase. J. Biochem. Biophys. Methods. 28, 173183.

31. Zhang, X.; Leeuwen, J.; Wichers, H.J.; Flurkey, W.H. (1999). Characterization of tyrosinase from the cap flesh of Portabella mushrooms. J. Agric. Food Chem. 47, 374-378. 